\title{
Endocarditis infecciosa en pacientes con daño hepático crónico. Serie de 4 casos clínicos
}

\author{
Dan Oksenberg R., Anna Castelli T. y Alberto Fica C.
}

\begin{abstract}
Hospital Clínico Universidad de
Chile, Santiago, Chile

Departamento de Medicina Sección de Gastroenterología (DOR) Sección de Infectología (ACT, AFC),
\end{abstract}

Recibido: 4 de agosto 2008 Aceptado: 9 de diciembre 2008

Correspondencia a: Alberto Fica Cubillos albertofica@gmail.com

\section{Infective endocarditis in patients with chronic hepatic failure. A four cases series}

Infective endocarditis and liver cirrhosis is an infrequent association. A retrospective study was performed in order to characterize predisposing factors, microbial causes and evolution. Medical records between 1995 and 2008 (June) were searched. Four cases were identified. In three cases liver cirrhosis was in stage Child A, and in all 4 there was a predisposing cardiac disease. Clinical manifestations were classical in 3 cases and in one presented as hepatic failure. Only in one case a typical agent was recovered. Other cases were associated to a nosocomial agent or Corynebacterium diphtheriae, and in one no agent was identified. One patient required valve replacement. Three patients recovered satisfactorily, all of them in Child A stage. One died of non-infectious causes (Child C). Infective endocarditis and liver cirrhosis is an infrequent association in clinical practice, it can be associated to unusual agents or clinical manifestations.

Key words: Bacterial endocarditis, liver cirrhosis, therapeutics, outcome.

Palabras clave: Endocarditis infecciosa, cirrosis hepática, tratamiento, evolución.

\section{Introducción}

$\mathrm{L}$ a presencia de una enfermedad hepática crónica determina un aumento en la susceptibilidad a padecer infecciones bacterianas. En orden decreciente de frecuencia, éstas son: peritonitis bacteriana espontánea, infecciones del tracto urinario y respiratorio y bacteriemias espontáneas. Estas infecciones se deben a la concomitancia de diferentes mecanismos facilitadores, tales como: cambios en la microbiota intestinal y en la barrera epitelial a este nivel (favorecen la traslocación bacteriana), disminución de la actividad del sistema retículo-endotelial, disminución de la capacidad opsónica del líquido ascítico, disfunción del sistema polimorfonuclear, estos fenómenos se conocen colectivamente como la inmunoparesia del paciente cirrótico ${ }^{1,2}$ y factores iatrogénicos (procedimientos invasores).

Las infecciones menos frecuentes en enfermos cirróticos, aunque relevantes por su pronóstico y tendencia a la recurrencia, afectan a los tejidos blandos, principalmente celulitis de las extremidades inferiores y de la región abdominal, en pacientes con edema periférico $y / o$ ascitis. La endocarditis infecciosa (EI) es una infección poco frecuente, probablemente sub-diagnosticada y mal definida en ellos ${ }^{1,3}$.

Los pacientes con enfermedad hepática crónica son más propensos a desarrollar EI que los sujetos que no padecen esta enfermedad. Su diagnóstico requiere de un alto grado de sospecha clínica debido a que las manifestaciones de la endocarditis suelen ser inespecíficas en los pacientes inmunocomprometidos y pueden estar atenuadas por la co-existencia de un deterioro sistémico secundario a la hepatopatía de base. Este grupo de pacientes no está bien reflejado en la literatura científica, y sólo se comunican series reducidas de pacientes, poco homogéneas y con resultados muy dispares, entre unas y otras ${ }^{4-6}$. Por tanto, no están bien definidas sus características clínicas y evolutivas. Al coexistir ambas enfermedades, es difícil aislar determinados factores que pueden influir en el pronóstico de estos pacientes como, por ejemplo, si la existencia de daño hepático previo al desarrollo de EI puede llegar a influir sobre su pronóstico vital, o si condiciona un curso clínico diferente en la historia natural de la infección.

El objetivo del presente trabajo descriptivo fue evaluar las características clínicas, espectro microbiológico y evolución de los pacientes cirróticos en quienes se diagnosticó una EI en nuestro hospital universitario.

\section{Pacientes y Métodos}

Detección de casos. Los casos fueron detectados mediante uso de datos personales de uno de los autores (DOR) y por búsqueda en bases de datos de la Unidad de Estadística del Hospital Clínico Universi- 
dad de Chile, desde 1995 al 2008 (junio). Se utilizó la clasificación internacional de enfermedades, incluyendo los términos endocarditis y cirrosis.

Análisis clínico. Se construyó una ficha de recolección de datos que incluyó factores demográficos, variables clínicas sobre la enfermedad de base, cardiopatía de base, procedimientos de riesgo, las características de la EI, etiología, evolución y tratamiento. El reconocimiento de la EI fue realizado de acuerdo a criterios estandarizados ${ }^{3}$. Por el pequeño número de la muestra, los datos fueron presentados en tablas sumatorias. El estadio de la cirrosis hepática se efectuó de acuerdo a la clasificación de Child $\mathrm{Pugh}^{4}$.

\section{Resultados}

Se logró identificar cuatro casos de EI asociados a patología hepática crónica, entre los años 2005 y 2008. La edad promedio fue 71,7 años con un claro predominio del sexo femenino (rango: 55 - 86 años). No se encontraron casos entre 1995 y el 2004.

Los datos muestran que los casos se asociaron predominantemente a cirrosis Child A (en tres de cuatro casos), con etiología alcohólica como causa principal. Sólo en un caso existía co-morbilidad relevante y que correspondió a insuficiencia renal crónica. En todos estos pacientes había una cardiopatía valvular predisponente y que involucraba, ya fuera una cardiopatía reumática, enfermedad valvular degenerativa, prótesis valvular o insuficiencia mitral (Tabla 1).

Se evaluó la realización de procedimientos, desde seis meses antes del desarrollo de la EI, dentro de los cuales fueron considerados: atención dental, endoscopia digestiva alta o baja y procedimientos percutáneos abdominales. Sólo en un paciente se obtuvo el antecedente de la instalación de un catéter pigtail percutáneo en el abdomen para el manejo de la ascitis (caso 4, Tabla 1). Fue además, el único paciente con historia de varias hospitalizaciones en los últimos 12 meses (Tabla 1).

En esta serie, las principales manifestaciones clínicas fueron las clásicamente asociadas a EI, tales como fiebre, esplenomegalia, embolias periféricas, fenómenos vasculares o baja de peso. Notablemente, todos los pacientes tenían soplos sistólicos al menos de intensidad III de VI (Tabla 2). En un caso, el cuadro se manifestó como descompensación de insuficiencia hepática y correspondió al paciente con cirrosis en etapa avanzada. En contraste, los casos con manifestaciones clásicas se asociaron a un daño hepático más leve (Tabla 2). Cabe destacar que en uno de estos pacientes no hubo aumento de la PCR y que en dos casos no hubo leucocitosis.

El diagnóstico de EI estuvo basado en los criterios de Duke, encontrando en todos los casos vegetaciones valvulares en el ecocardiograma. En tres de estos casos, el diagnóstico se obtuvo por la conjunción de un criterio mayor y tres menores (Tabla 2). Los criterios menores identificados fueron cardiopatía predisponente, fiebre $>38^{\circ} \mathrm{C}$, embolia esplénica o del SNC, fenómenos vasculares o evidencia microbiológica sin elementos para criterio mayor o esplenomegalia.

En tres de los cuatro casos, estaba involucrada la válvula mitral y en el mismo número de pacientes se pudo precisar la etiología de la EI. Sólo en un caso se detectó un agente típico (Streptococcus del grupo viridans) y en los otros dos con información disponible, se identificaron agentes inhabituales correspondiendo a Corynebacterium sp y Staphylococcus coagulasa negativa resistente a meticilina (Tabla 2). En el paciente en el cual no se precisó la etiología, se había utilizado recientemente macrólidos y gentamicina antes del diagnóstico.

\begin{tabular}{|c|c|c|c|c|}
\hline & Caso 1 & Caso 2 & Caso 3 & Caso 4 \\
\hline Edad (años) & 86 & 71 & 55 & 75 \\
\hline Sexo $(F / M)$ & $\mathrm{F}$ & M & $\mathrm{F}$ & $\mathrm{F}$ \\
\hline Clasificación Child-Pugh & A & A & A & C \\
\hline Etiología $\mathrm{DHC}^{*}$ & VHB & Sin causa & Alcohol & Alcohol \\
\hline Co-morbilidad & No & No & No & IRC \\
\hline Factor de riesgo cardiovascular & Prótesis valvular biológica & Estenosis aórtica degenerativa & Insuficiencia mitral & $\begin{array}{l}\text { Cardiopatía reumática con } \\
\text { enfermedad mitral y aórtica }\end{array}$ \\
\hline Procedimientos & No & No & No & Sí \\
\hline Hospitalizaciones en últimos 12 meses, $\mathrm{n}$ & Ninguna & 1 & Ninguna & 5 \\
\hline
\end{tabular}




\begin{tabular}{|c|c|c|c|c|}
\hline & Caso 1 & Caso 2 & Caso 3 & Caso 4 \\
\hline Manifestaciones clínicas & $\begin{array}{l}\text { Fiebre } \\
\text { Baja de peso } \\
\text { IC } \\
\text { Embolias no SNC } \\
\text { Fenómenos vasculares }\end{array}$ & $\begin{array}{l}\text { Fiebre } \\
\text { Esplenomegalia }\end{array}$ & $\begin{array}{l}\text { Fiebre } \\
\text { Embolias SNC } \\
\text { Esplenomegalia }\end{array}$ & $\begin{array}{l}\text { IC } \\
\text { Esplenomegalia } \\
\text { Descompensación de la } \\
\text { cirrosis }\end{array}$ \\
\hline Examen cardiovascular & Soplo sistólico mitral & $\begin{array}{l}\text { Soplo sistólico eyectivo } \\
\text { IVNI en foco aórtico }\end{array}$ & $\begin{array}{l}\text { Soplo sistólico III/NI en } \\
\text { área precordial }\end{array}$ & $\begin{array}{l}\text { Soplo sistólico foco aórtico } \\
\text { III/VI irradiado al cuello }\end{array}$ \\
\hline Laboratorio & $\begin{array}{l}\text { PCR elevada } \\
\text { L } 10.500 / \mathrm{mm}^{3}\end{array}$ & $\begin{array}{l}\text { PCR elevada } \\
\text { L normales }\end{array}$ & $\begin{array}{l}\text { PCR elevada } \\
\mathrm{L}>10.500 / \mathrm{mm}^{3}\end{array}$ & $\begin{array}{l}\text { PCR normal } \\
\text { L normales }\end{array}$ \\
\hline Ubicación de vegetación & Mitral & Aórtico & Mitral & Mitral \\
\hline Etiología & No establecida & $\begin{array}{l}\text { Streptococcus grupo } \\
\text { viridans }\end{array}$ & Corynebacterium sp & $\begin{array}{l}\text { Staphylococcus coagulasa } \\
\text { negativa meticilina resistente }\end{array}$ \\
\hline Tratamiento & $\begin{array}{l}\text { Ampicilina } \\
\text { Ceftriaxona } \\
\text { Gentamicina }\end{array}$ & $\begin{array}{l}\text { Ceftriaxona } \\
\text { PNC } \\
\text { Gentamicina }\end{array}$ & $\begin{array}{l}\text { Gentamicina } \\
\text { PNC } \\
\text { Ampicilina } \\
\text { Vancomicina }\end{array}$ & $\begin{array}{l}\text { Penicilina } \\
\text { Cloxacilina } \\
\text { Gentamicina } \\
\text { Vancomicina } \\
\text { Teicoplanina }\end{array}$ \\
\hline Cardiocirugía & No & No & $\begin{array}{l}\text { Sí, reemplazo valvular mitral } \\
\text { Embolias múltiples }\end{array}$ & No \\
\hline Complicaciones & No & $\begin{array}{l}\text { Sí } \\
\text { Persistencia de fiebre } \\
\text { Re-hospitalización }\end{array}$ & $\begin{array}{l}\text { Sí } \\
\text { Secundarios a cardiocirugía } \\
\text { Infección nosocomial } \\
\text { recurrente }\end{array}$ & $\begin{array}{l}\text { Sí } \\
\text { S. Stevens Johnson } \\
\text { Infección por C. difficile } \\
\text { Progresión de DHC }\end{array}$ \\
\hline Evolución & Favorable & Favorable & Favorable & Muerte \\
\hline Criterio El & $\begin{array}{l}\text { El definida } \\
\text { (1 mayor }+3 \text { menores) }\end{array}$ & $\begin{array}{l}\text { El definida } \\
\text { (1 mayor }+3 \text { menores) }\end{array}$ & $\begin{array}{l}\text { El definida } \\
\text { (1 mayor }+3 \text { menores) }\end{array}$ & $\begin{array}{l}\text { El definida } \\
\text { ( } 2 \text { mayores) }\end{array}$ \\
\hline
\end{tabular}

Los pacientes fueron tratados con diferentes esquemas que, en general, estaban adaptados a las recomendaciones terapéuticas internacionales con uso de $\beta$-lactámicos y aminoglucósidos (Tabla 2). En dos casos se utilizaron glicopéptidos, en un caso para el manejo de infecciones nosocomiales y en el caso 4 por la resistencia del agente que provocó la EI.

En tres pacientes se observaron complicaciones y que correspondieron a: persistencia de la fiebre con necesidad de re-hospitalización, infección nosocomial recurrente y síndrome de Stevens Johnson asociado a infección por Clostridium difficile, con progresión del daño hepático avanzado y muerte. Uno de los casos requirió cirugía de reemplazo valvular por embolias múltiples.

La evolución fue favorable en tres casos y una paciente falleció por progresión de su enfermedad hepática a pesar de haber respondido al tratamiento de la endocarditis.

\section{Discusión}

El hígado desempeña un importante papel en la defensa contra las infecciones bacterianas, aumentando la susceptibilidad a padecerlas en aquellos pacientes con cirrosis ${ }^{2,7,8}$. En particular, la hepatopatía crónica se ha relacionado con un aumento de la susceptibilidad a desarrollar una EI ${ }^{9}$. En la cirrosis, a raíz de la hipertensión portal se produce éxtasis sanguínea y derivación de la sangre por colaterales venosas perihepáticas, con lo que se facilita la persistencia de bacteriemias y se incrementa la vulnerabilidad a la endocarditis.

En la literatura científica se describen las características y las implicaciones pronósticas de un elevado número de sub-poblaciones de pacientes afectados por EI, tales como los pacientes diabéticos o los ancianos $^{10}$, pero existen escasos estudios que relacionen la EI con la enfermedad hepática crónica, existiendo sólo 
comunicaciones de series reducidas, con una gran disparidad de pacientes y resultados contradictorios. Una de las primeras series, publicada hace más de 30 años, fue la de Buchbinder et $\mathrm{al}^{11}$, en la cual se reportaron 14 pacientes cirróticos alcohólicos con una combinación de neumonía, meningitis y EI; Streptococcus pneumoniae fue el agente más frecuente en 10 de los casos. En la experiencia de McCashland y cols ${ }^{12}$, con una serie de ocho pacientes, la EI fue más frecuente en mujeres, afectando característicamente a la válvula mitral y el microorganismo mayoritariamente aislado fue Staphylococcus aureus. Para Otones y cols ${ }^{7}$, que analizó a 16 pacientes, el microorganismo causal más frecuente fue Enterococcus sp, en relación con infecciones urinarias o gastrointestinales, y Streptococcus agalactiae (grupo B) en pacientes con hepatopatía alcohólica, aunque el origen de la infección fue desconocido en $61 \%$ de los casos. La localización predominante fue en la válvula aórtica y la distribución por sexos, similar entre varones y mujeres. En la serie más grande publicada, de Pérez De Isla y cols ${ }^{9}$, predominaron pacientes jóvenes, con alta incidencia de drogadicción parenteral y, por ende, hubo alta frecuencia de EI de válvula tricúspide, siendo $S$. aureus el agente predominante. La mortalidad en este grupo fue de $40 \%$ entre pacientes cirróticos.

En nuestra pequeña serie, no hubo pacientes bajo 50 años de edad, la mayoría fueron clasificados como Child A, pero todos con hipertensión portal; la mitad eran alcohólicos y todos tuvieron una cardiopatía valvular susceptible, principalmente de la válvula mitral, predominando microorganismos inhabituales por sobre el género Streptococcus. Asimismo, todos ellos tenían soplo sistólico y la mayor parte presentó fiebre persistente como síntoma cardinal, con PCR elevada, embolias periféricas e insuficiencia cardíaca, requiriendo cirugía sólo en un caso. Cabe mencionar que la esplenomegalia es un hallazgo de interpretación cuestionable en estos casos, debido a la posibilidad de que sea secundaria a hipertensión portal o a la endocarditis. En esta serie, sólo una paciente falleció, siendo la única en categoría Child $\mathrm{C}$ de la serie. Esta paciente había tenido hospitalizaciones previas y había sido sometida a procedimientos invasores (pigtail peritoneal), lo que determinó la presencia de un agente nosocomial.
Múltiples factores pueden contribuir al desarrollo de EI en pacientes cirróticos con hipertensión portal. Primero, los shunts porto-sistémicos aumentan el riesgo de bacteriemia espontánea, sin presencia de sepsis, lo que se ha reportado hasta en $20 \%$ de pacientes con cirrosis descompensada ${ }^{1}$. Segundo, la desnutrición, frecuente en el paciente con cirrosis, produce un claro defecto en la inmunidad celular, con alteración de la quimiotaxis de los PMN, de la opsonización y de la fagocitosis $^{2,12}$. Tercero, en la cirrosis descompensada aumenta la probabilidad de procedimientos invasores que incrementan el riesgo de bacteriemia, tal como sucedió en uno de nuestros pacientes.

En suma, dentro de los diagnósticos diferenciales de un deterioro agudo en un paciente cirrótico, con un cuadro febril, soplo sistólico y PCR elevada, sobre todo con cardiopatía susceptible y antecedente de algún procedimiento invasor previo, debe considerarse la EI, teniendo en cuenta la posibilidad de microorganismos inusuales en esta población, los que, sin embargo, probablemente responderán al tratamiento clásico con un $\beta$ lactámico y un aminoglucósido.

\section{Resumen}

La asociación entre daño hepático y endocarditis infecciosa es infrecuente. Para analizar los factores predisponentes de esta asociación, la etiología microbiana y evolución clínica, se efectuó un análisis retrospectivo de los egresos por endocarditis infecciosa en pacientes con cirrosis hepática desde 1995 a junio de 2008. Se identificaron cuatro casos, asociados a categoría Child A en tres y en todos había una cardiopatía predisponente. Las manifestaciones clínicas fueron clásicas excepto en un caso que se presentó como descompensación hepática. Sólo un caso se asoció a un agente típico, otros a un agente nosocomial y Corynebacterium diphtheriae. En un caso no se identificó la etiología. Uno de los pacientes requirió cirugía de reemplazo valvular. Tres pacientes se recuperaron (Child A) y el paciente en categoría Child C falleció. Aunque infrecuente, la asociación cirrosis y endocarditis ocurre en la práctica clínica, se puede asociar a agentes inhabituales y tener manifestaciones encubiertas. 


\section{Referencias}

1.- Navasa M, Rodès J. Bacterial infections in cirrhosis. Liver Int 2004: 24: 277-80.

2.- Fica A. Diagnóstico, manejo y prevención de infecciones en pacientes con cirrosis hepática. Rev Chil Infect 2005; 22: 63-74.

3.- Baddur L M, Wilson W R, Bayer A S, Fowler V G, Bloger A F, Levison M E, et al. Infective endocarditis. Diagnosis, antimicrobial therapy, and management of complications. A statement for healthcare professionals from the Committee on Rheumatic fever, Endocarditis, and Kawasaki disease, Council on Cardiovascular disease in the young, and the Councils on Clinical Cardiology, Stroke, and Cardiovascular Surgery and Anesthesia,
American Heart Association. Circulation 2005; 111: e394-e443

4.- Pugh R N, Murray-Lyon I M, Dawson J L, Pietroni M C, Williams R. Transection of the oesophagus for bleeding oesophageal varices. Br J Surg 1973; 60: 646-9.

5.- Snyder N, Atterbury C E, Correia J P, Conn $\mathrm{H}$ O. Increased concurrence of cirrhosis and bacterial endocarditis. Gastroenterology 1977; 73: 1107-13.

6.- Denton J H, Rubio C, Velazquez J, De Arellano G R. Bacterial endocarditis in cirrhosis. Dig Dis Sci 1981; 26: 935-7.

7.- Otones J, Fernández Clúa M A, Castrillo J M, Fernández Guerrero M L. Endocarditis infecciosa en pacientes con cirrosis hepática. Med Clin (Barc) 1989; 93: 561-4.

8.- Mylonakis E, Calderwood S B. Infective endocarditis in adults. N Engl J Med 2001;
345: 1318-30.

9.- Pérez de Isla L, Zamorano J L, Almería C, Rodrigo J L , Piedra I, Aubele A, et al. Infective endocarditis in patients with chronic liver disease: Clinical and prognostic assessment. Rev Esp Cardiol 2003; 56: 794-800.

10.- Castillo J C, Anguita M P, Torres F, Siles J R, Mesa D, Vallés F. Factores de riesgo asociados a endocarditis sin cardiopatía predisponente. Rev Esp Cardiol 2002; 55: 304-7.

11.- Buchbinder N A, Roberts W. Alcoholism: An important but unremphasized factor predisposing to infective endocarditis. Arch Intern Med 1973; 132: 689-92.

12.- McCashland T M, Sorrell M F, Zetterman R K. Bacterial endocarditis in patients with chronic liver disease. Am J Gastroenterol 1994; 89: 924-7. 